Tobacco dependence; the whole story

\author{
Hawari FI
}

\begin{abstract}
:
The use of tobacco dates back to hundreds of years and is considered highly addictive. Nicotine is the predominant substance that causes tobacco dependence. Nicotine exerts its effect via similar neurological pathways used by other recreational drugs resulting in high level of dependence. All forms of exposure to tobacco including active use of tobacco, second-hand as well as third-hand exposure to tobacco smoke are known to be harmful. Tobacco is the only risk factor that is common between all non-communicable diseases including cardiovascular diseases, respiratory illnesses, cancer and diabetes mellitus. International consensus regarding the harms of tobacco is now evident. Many international organizations are mapping the way for the end of tobacco. Until then, aggressive treatment for those subjects interested in quitting must be provided in order to prevent a significant surge in non-communicable diseases especially in low income countries. Tobacco dependence is a chronic relapsing disorder that requires a multidisciplinary approach using psychological and pharmacological techniques.
\end{abstract}

Keywords: tobacco dependence, tobacco harms, tobacco control, tobacco dependence treatment

\section{The history of tobacco:}

Tobacco is a naturally deadly plant that initially was grown only in North and South America. It belongs to the same family as potatoes and pepper. Following the discovery of America, sailors brought tobacco with them to Europe and then to the rest of the world. In the 1500's it was thought that tobacco can cure all diseases and was promoted as such by physicians and recommended to be taken daily. Later in the 1600's, tobacco became so popular and was used instead of money to complete business transactions. During those times the first hints that tobacco might be harmful began to surface. In 1610 the first evidence that tobacco might be addictive and that smokers might be interested in quitting was concluded from a statement made by Sir Francis Bacon who noted that " trying to quit the bad habit was really hard". By mid-1600's it became morally unacceptable to smoke in certain states of the United States of
America such as Massachusetts due to the fact the tobacco may be harmful ${ }^{1-2}$.

In 1760, Pierre Lorillard established a company in New York City to process tobacco, cigars, and snuff and became the oldest tobacco company. The tobacco industry became well established since then and played a role in financing governmental actions including military operations. Following that and in 1826 specifically, nicotine was isolated in its pure format and was declared few years later poisonous and that it can be used as an insecticide. In 1836 the first statement was made regarding the lethal effect of nicotine as a chemical that might be able to kill a human being. Cigarettes were firs manufactured in 1847. By the year 1900 cigarettes became the major tobacco product made and sold. In 1901 for example, 3.5 billion cigarettes and 6 billion cigars were sold. Cigarettes continued to spread after that to a point that they were part of soldiers' rations during World War II. Finally, in

Correspondence to: : Feras I. Hawari, MD, FCCP, Chief, Section of Pulmonary and Critical Care, Director, Cancer Control Office, King Hussein Cancer Center, Jordan email: fhawari@KHCC.JO 
1964 the first USA Surgeon General report came out carrying the title "Smoking and Health" focusing on health effects of tobacco and providing the first document for governments to start regulating and controlling the spread of tobacco. Later, more Surgeon General reports began to shed the light on the harmful effects of tobacco till the year 1982 when second hand smoke exposure was declared a risk factor for the development of lung cancer resulting in the gradual banning on smoking in public places. Throughout the years, all efforts by governments to curb the spread of tobacco were constantly faced by counter novel and misleading tactics by the tobacco industry that encouraged the use to tobacco through marketing to teenagers, females using products designed specifically to attract such consumers. In addition, they started diversifying their products to include food and clothing. Lately, the tobacco industry moved into a new line of production; electronic cigarettes in order to face global efforts aiming at putting an end to this industry and reducing tobacco prevalence to less than $5 \%$ by 2040 . Worldwide, 3.8 million hectares of agricultural land are used in tobacco agriculture distributed over 124 countries. China grows $43 \%$ of the world's tobacco cigarettes accounting for $92 \%$ of the value of all tobacco products sold globally.

\section{Forms of tobacco and tobacco smoke exposure:} Tobacco is used either by burning dry or processed leaves of the tobacco plant and inhaling the smoke or as smokeless tobacco which is usually consumed either orally or nasally, without burning or combustion. Both forms of tobacco consumption increase the risk of cancer and lead to nicotine addiction. Combustion, however, uses heat to create new chemicals that are not found in unburned tobacco such as carbon monoxide, tobacco-specific nitrosamines (TSNAs) and benzopyrene, and allows them to be absorbed through the lungs. ${ }^{1}$

Manufactured cigarettes are the most commonly consumed tobacco products worldwide. ${ }^{1}$ They consist of tobacco that is processed with chemicals and flavors such as menthol and rolled into a paper-wrapped cylinder. As it burns from one end, smoke is inhaled from the other end through a cellulose acetate filter. Cigars are made of air-cured and fermented tobaccos rolled in tobacco-leaf wrappers. This process of aging and fermentation result in high concentrations of carcinogenic compounds inhaled by smokers and they amount to higher concentration than in cigarettes. Waterpipe, also known as shisha, hookah, narghile, or hubble-bubble constitutes now a world-wide epidemic. ${ }^{3}$ The additional use of charcoal in waterpipe smoking to indirectly heat and burn tobacco represents a significant added risk that contributes to the carcinogenicity of this method of smoking. When smoking waterpipe, smoke is drawn through the water to be partially cooled and inhaled into the lungs through a hose. Flavored tobacco maybe used too. Kreteks, another form of smoking tobacco, are usually clove-flavored and contains eugenol which has an anesthetic effect. ${ }^{4}$ Flavoring in general usually allow for deeper and thus more harmful smoke inhalation. This form of smoking tobacco is commonly used in countries in Southeast Asia such as Indonesia. Contrary to the belief of the general public, roll-your-own cigarettes which are handfilled by the smoker from fine-cut loose tobacco and a cigarette paper contains high concentrations of tobacco particulates, tar, nicotine, and TSNAs resulting in increased risk for developing cancers of the head and neck, lungs, and esophagus. It is most prevalent in Europe and New Zealand. Bidis on the other hand, consist of a small amount of crushed tobacco, hand-wrapped in dried temburni or tendu leaves, and tied with string. Bidis deliver more tar and carbon monoxide than manufactured cigarettes due to the fact that users should puff harder to keep them lit. Bidis are most prevalent in South Asia and India. Pipes are made of briar, slate, clay, or other substances. After placing tobacco in a special bowl, it is burned and smoke is inhaled through the stem. Pipes are prevalent worldwide. Sticks are made from sun-cured tobacco and wrapped in cigarette paper.

Smokeless tobacco forms include chewing tobacco, moist tobacco and dissolvable tobacco. All these forms deliver nicotine through buccal mucous membranes. Dry snuff is inhaled through the nose or taken orally.

Second-hand smoking (passive smoking) is another form of exposure to tobacco smoke. This type of exposure does not only contribute to the initiation of smoking, development of tobacco dependence $^{5}$ and significant irritation to those who are exposed to it, but it also contributes to significant mortality and morbidity in the community. ${ }^{6}$ Passive smoking can significantly elevate the level of carbon monoxide, increase risk of lung cancer, coronary artery disease and 
sudden cardiac arrests in those expose to it. ${ }^{7}$ In the 1960s the adverse effects of maternal smoking on the developing fetus and on children exposed to secondhand smoke in smoking households were reported. ${ }^{8,9}$ Those fetuses who were exposed to environmental tobacco smoke suffered from decreased lung function. ${ }^{10}$ All that led to a conclusion by the USDHHS 1986, that "Simple separation of smokers and nonsmokers within the same air space may reduce, but does not eliminate, exposure of nonsmokers to environmental tobacco smoke". Such conclusion was then the basis for strict implementation of banning the exposure to second hand smoke in public places. ${ }^{11}$

Another form of exposure to tobacco smoke is the newly described third-hand smoking. This refers to the chemical and products that precipitate on the surfaces after second hand smoke is cleared. ${ }^{12}$ Third-hand smoke contaminate surfaces, furniture and clothing with carcinogenic chemicals such as radioactive polonium-210 and tobacco-specific nitrosamines. ${ }^{13,14}$

These chemical could potentially pose great deal of danger to infants and young children who are more likely to crawl and eat with their hands without washing them. Research is underway to expose the real health risks associated with thirdhad smoking. ${ }^{15}$

\section{Tobacco in the region: Epidemiology, expected health tolls and finance}

Despite efforts to control the spread of tobacco, currently $20 \%$ of the world's population smokes with mails constituting around $80 \%$ of the total percentage of smokers resulting in around one billion active smoker. Such large number of smokers is not only causing a rise in morbidity and mortality due to various diseases that result directly from smoking, but also contributing significantly to death resulting from second hand smoking especially in women and children While current death toll from second hand smoking is estimated to be at 600,000 individuals annually, ${ }^{1}$ it is also estimated that $75 \%$ of these deaths are among women and children. In general, males contribute to the majority of percentage of smokers in the world. More than half the countries of the world have a female smoking prevalence rate of less than $10 \%$. Smoking rates among boys and girls are more comparable and differ by less than five percentage points in almost half of the world's countries. Smokers consumed nearly 5.9 trillion cigarettes in 2009. Tobacco taxation is considered a significant source of revenue income for most countries. Despite the fact that governments collect nearly $\$ 133$ billion in tobacco tax revenues each year, they spend less than $\$ 1$ billion on tobacco control. Further increase in revenue is expected if illicit trade were to be eliminated. Governments worldwide would gain at least $\$ 31.3$ billion a year in tax revenue. The World Health Organization (WHO) recommends that at least $70 \%$ of the retail price of tobacco products come from excise taxes. At least $86 \%$ of WHO member states imposed a tobacco excise tax, and at least $14 \%$ use a portion of tobacco tax revenue for health purposes. Some countries are now envisioning an end game for tobacco, with prevalence targets of under $5 \%$. The WHO Frame Work Convention on Tobacco Control (FCTC) treaty covers $87.4 \%$ of the world population. Approximately 3.8 billion people are covered by at least one of the six MPOWER strategies that will be discussed below at the highest level of achievement. The number of people protected by comprehensive smoke-free laws has doubled from 2008 to $2010{ }^{1}$

\section{Tobacco initiation and dependence:}

Tobacco initiation typically occurs during childhood or adolescence. It is an acquired social behavior. ${ }^{16}$ Social learning occurs in children as they adopt behaviors in part through observation of parents, peers, and other role models. During the teenage years, peer pressure becomes the dominant social influence. ${ }^{16}$ Media plays an important role in promoting and normalizing the appearance and the behavior of smokers through projecting famous figures smoking in public. Initially, initiation is mostly voluntary, however, upon the development of addiction, self-control can become seriously difficult and impaired. The cycle of nicotine addiction starts when nicotine containing products are used for pleasure and enhancing mood and performance. As tolerance and physical dependence develop over time continuous use of nicotine products are used to self-medicate withdrawal symptoms in addition to the above sought after effects. ${ }^{17}$ Tobacco dependence and withdrawal syndromes are classified as substance use disorders under World Health Organization International Statistical Classification of Diseases and Related Health Problems (ICD 10), ${ }^{18}$ an important step in justifying and encouraging governments to offer treatment to smokers. In general, dependence 
develops when the neurons adapt to the repeated drug exposure and only function normally in the presence of the drug. ${ }^{19}$ Tobacco dependence is driven by the highly addictive nature of nicotine. As a psychoactive drug, nicotine induces euphoria, serves as a reinforcer of its use and act as both a stimulant and a depressant. Strong and overwhelming withdrawal symptoms develop in its absence. Tobacco dependence fulfils all Diagnostic and Statistical Manual of Mental Disorders, 4th Edition criteria for substance abuse. It is ranked third after heroin and cocaine and higher than alcohol and cannabis in its ability to cause dependence. ${ }^{20}$ The combination of its highly addictive property as well as the severe harms that it inflicts on its active users as well as the severe detrimental health effects second and third hand smoking have on the population, caused religious Islamic leaders in many Muslim countries such as Jordan, Egypt, many countries in Gulf Cooperation Council as well as Islamic countries in southeast Asia to issue a Fatwa that using tobacco products is forbidden according to Islamic rules (Haram). ${ }^{21,22,23,24}$ It is important to note that nicotine mechanism of action and the targeted areas in the brain are similar to other recreational drugs such as cocaine which its principle mechanism of action is thought to be by targeting areas in the brain such as the nucleus accumbens and increasing levels of dopamine which in return result in the desirable effects and inhibit the withdrawal symptoms that may results from abstinence from the drug. ${ }^{25}$

Nicotine reaches the brain through either the lungs when smoked or mucous membranes when smokeless tobacco forms are used. Although the levels of many substances are reported to increase in the brain upon exposure to tobacco smoking such as serotonin and endogenous opiates, however, dopamine remains the main chemical involved in the process of positive reinforcing aspects of nicotine addiction and the desired feelings sought by those who use tobacco. As nicotine reaches the brain it binds to a special receptor known as $\alpha_{4} \beta_{2}$ nicotinic acetylcholine receptor (nAChR). Located in the ventral tegmental region and results in the release of dopamine. ${ }^{26} 27282930313233$ As nicotine binds to $\alpha_{4} \beta_{2}$ nicotinic acetylcholine receptor (nAChR) occupancy on glutamatergic terminals, glutamate, an excitatory neurotransmitter, is released which results in an increased release of dopamine in the nucleus accumbens and the frontal cortex. ${ }^{34} 3536373839$ In addition Nicotine binds to $\alpha_{4} \beta_{2}$ nicotinic acetylcholine receptor (nAChR) occupancy on gamma-aminobutyric acid (GABA)-releasing terminals. ${ }^{40,38}$

This binding cause and increase in the levels of GABA, an inhibitory neurotransmitter. Furthermore, nicotine binds to a specific receptor in regions of the brain such as the nucleus accumbens and result in the production of dopamine. ${ }^{41}$

These chain reactions start as nicotine reaches the brain in 10-20 seconds after inhalation mainly due to due to the large surface area in the lung available for absorption and is the main basis for the development of nicotine dependence. ${ }^{42}$ In general, nicotine dependence follows a similar definition of dependence that occurs with other substances and that is characterized by both the persistence of a drug-seeking behavior and the emergence of withdrawal symptoms upon the abrupt cessation of nicotine administration. ${ }^{41}$ In the end, chronic nicotine exposure result in a neuro-biologic adaptation and desensitization of the receptors with the need to increase those receptors through further increase in the quantities of tobacco consumed. However, not all forms of nicotine delivery pose an equal risk in establishing or maintaining nicotine addiction. Nicotine replacement therapy used in treating tobacco dependence for example is less likely to cause dependence and easier to discontinue once the treatment goals are achieved. Although it has been always emphasized that nicotine is the most important chemical in cigarettes that contributes to its highly addictive properties, other compounds such as acetaldehyde, ammonia compounds, and menthol also make cigarettes more addictive through increasing free-base nicotine, making it easier to produce larger puffs (filter-tip ventilation) and other factors that reduce the concerns for smokers and increase the attractiveness of the products. $^{43}$

Nicotine is metabolized primarily by the liver enzymes CYP2A6, UDP-glucuronosyltransfease (UGT), and flavin-containing monooxygenase (FMO). Many factors influence the metabolism of nicotine such as genetic factors, diet, age, sex, use of estrogen-containing hormone preparations, pregnancy and kidney disease, other medications, and smoking itself. ${ }^{44}$ Nicotine is further metabolized to cotinine, which may be measured in blood, urine, saliva, hair, or nails. Cotinine levels are used to distinguish smokers from nonsmokers. Levels exceeding $3 \mathrm{ng} \mathrm{ml}-1$ indicate 
active smoking status in countries with low exposure to second hand tobacco smoke exposure.

Second hand smoke exposure is believed to play an important role in the occupancy of $\alpha_{4} \beta_{2}$ nicotinic acetylcholine receptor occupancy. Recent evidence ${ }^{45}$ utilizing Positron emission tomography scanning measured whether moderate SHS exposure results in brain $\alpha_{4} \beta_{2}{ }^{*}$ nicotinic acetylcholine receptor occupancy in smokers and nonsmokers. The study concluded that nicotine from SHS exposure results in substantial brain $\alpha_{4} \beta_{2}{ }^{*}$ nAChR occupancy in smokers and nonsmokers. In addition, the finding suggested that such occupancy would be sufficient to deliver a priming dose of nicotine to the brain that contributes to continued cigarette use in smokers. It was also important to note that while moderate exposure tested in this study was sufficient to cause an increase in plasma nicotine concentration of approximately $0.2 \mathrm{ng} / \mathrm{mL}$ and a mean $19 \%$ brain $\alpha_{4} \beta_{2}{ }^{*}$ nAChR occupancy in young adults heavy SHS exposure (in enclosed rooms with multiple smokers) demonstrated increases in plasma nicotine levels greater than $2 \mathrm{ng} / \mathrm{mL}$ and greater than $70 \% \quad \alpha_{4} \beta_{2}{ }^{*}$ nAChR occupancy. ${ }^{46}$ These alarming findings have greater implication in countries where second hand exposure control are not implemented resulting in significant exposure in nonsmokers especially prepubescent children and infants who have a 1-minute ventilation per kilogram of bodyweight that is approximately 2 to 3 times higher than adults increases in plasma nicotine concentration and occupancy of brain $\alpha_{4} \beta_{2}{ }^{*}$ nAChRs from similar levels of SHS exposure may be even greater for children than for adults, thus setting them up to be dependent on nicotine during early childhood. Such studies that link SHS exposure and craving in smokers as well as priming nonsmokers especially children is highly relevant to public policy and laws that aim at limiting SHS exposure in closed public places. ${ }^{47,48,49}$

\section{Health effects of tobacco:}

Every year more than 5 million people die from tobacco-related diseases. By the year 2030, this number is expected to near 10 million..$^{50}$ With high income countries making efforts to limit the spread of tobacco in their areas and consequently succeeding in decreasing the prevalence of smoking, it is expected that more than $80 \%$ of these tobacco-related deaths will occur in low income countries. ${ }^{1}$

Tobacco is currently the most preventable cause of death and is the only risk factor that is common among all non-communicable diseases namely cardiovascular disease, cancer, respiratory illnesses and diabetes mellitus. However, the World Economic Forum estimates that the cost of these diseases in low income countries is expected to exceed USD 20 trillion over the next 15 years, thus exerting enormous pressures on countries with limited resources to enforce their tobacco control regulations. ${ }^{51}$ NCDs related deaths are expected to increase by more than $25 \%$ in low income countries over the next 15 years. ${ }^{52}$

Cardiovascular diseases occupy the number one spot among all NCDs that cause death in humans. The relation between tobacco use and cardiovascular diseases was recognized in the first surgeon general report in $1964 . .^{53}$ Cigarette smoking accelerates atherosclerosis and contributes to cardiovascular diseases through many mechanisms that precipitate thrombosis, hemorrhage, or vasoconstriction resulting in the end in vascular occlusion and ischemia. Cigarette smoking affects blood lipids profile and hemostasis. ${ }^{41}$ Smokers have lower concentration of high density lipoproteins, a risk factor for coronary artery diseases. Carbon monoxide resulting from the combustion of tobacco and that is significantly elevated in the blood of smokers is known to have an affinity for hemoglobin of more than 200 times of that of oxygen, thus reducing directly oxygen delivery to the tissues. Overall, smoking causes CVD through multiple mechanisms including: endothelial dysfunction, increasing prothrombotic effect, enhanced platelet activation in response to different stimuli, inflammation through activation of NF- $\mathrm{KB}$ pathway, ${ }^{54}$ altered lipid metabolism, increased demand for myocardial oxygen and blood. All these proposed mechanisms would result in a decreased supply of myocardial blood and oxygen either directly through narrowing of the lumen (due to atherogenesis plaque formation and vascoconstriction) or through the increased demand (due to nicotine mediated sympathetic stimulation and increased heart rate, blood pressure and myocardial contractility). The 2010 Surgeon General's report ${ }^{55}$ reported an increase in CHD risk with more cigarettes smoked per day only up to about 25 cigarettes. Others showed such relation to continue up to 40 cigarettes per day. ${ }^{56}$ These effects are not exclusive for active tobacco 
smoking, In fact, second- hand smoke is also associated with chronic inflammation and a nonlinear dose-response relationship between such exposure and cardiovascular effects. ${ }^{57}$ Jefferis et al showed that serum cotinine in nonsmokers was positively associated with white blood cell count and with levels of CRP, IL-6, fibrinogen, and matrix metalloproteinase 9. The CRP levels of nonsmokers were about one-third lower than the levels of active smokers, but CRP levels increased more sharply among nonsmokers at higher exposure levels. ${ }^{58}$ These findings emphasize again the benefits of banning smoking in public places. In addition to coronary heart disease, a growing sufficient body of evidence indicates that smoking causes sudden death,,$^{59}$ aortic aneurysms, ${ }^{60}$ and peripheral vascular disease. ${ }^{61,62}$ There is a doseresponse relationship between smoking and cerebrovascular disease, ${ }^{63,64,65}$ and a new sufficient evidence that demonstrates a causal relationship between exposure to secondhand smoke and increased risk of stroke up to $30 \% .^{66,67}$

Smoking and cancer: It has been established that smoking increases the risk for certain cancers such as head and neck cancers, lung cancer, urinary bladder cancer and leukemia. Tobacco smoke contains more than 7,000 chemicals, and at least 69 of these can cause cancer. ${ }^{68}$ An example of these chemicals include aromatic amines, polycyclic aromatic hydrocarbons (PAHs); tobacco-specific nitrosamines; formaldehyde, acetaldehyde, 1,3-butadiene, and benzene. When inhaled, these substances cause DNA damage, inflammation and mutations in oncogenes and tumor suppressor genes leading to loss of normal growth controlled mechanisms. ${ }^{55}$ Recently, new evidence concluded a causal relationship between colon cancer and liver cancer. ${ }^{41}$ In addition, evidence is suggestive that exposure in both its forms, active smoking and exposure to second-hand tobacco smoke might cause breast cancer. In general, smoking has been associated with decreased survival in patients with a variety of cancers such as head and neck, breast, colorectal cancer, prostate cancer and others. ${ }^{69}$ This negative effect on survival outcome is multifactorial. For example, Smoking has been associated with poor nutrition, co-morbidities, impaired immune function and accelerated carcinogenesis and disease progression. ${ }^{70,71,72,73,74}$ Second, patients who continue to smoke while they are receiving chemo and radiotherapy are at risk of receiving suboptimal therapy for their cancer $^{75}$ and have a higher chance of developing adverse events related to these modalities of treatment. ${ }^{76,77,78}$ Third, the development of a second malignant primary tumor and the negative impact of smoking on the life of cancer survivors are other significant risks that cancer patients who continue to smoke must deal with. ${ }^{79,80,81}$

Smoking and pulmonary diseases: smoking is known to cause and affect many respiratory illnesses such as chronic obstructive pulmonary disease (COPD), asthma, tuberculosis and pulmonary fibrosis. Smoking causes all elements of the COPD phenotypes including emphysema and damage to the airways of the lung. Smoke recruits inflammatory cells such as macrophages and liberates proteases from viable lung cells which in return disrupt the function of protease inhibitors like $\alpha 1$-antitrypsin. This results in facilitating the effect of proteases and the destruction of extracellular matrix. Evidence is suggestive that women who smoke are more susceptible to develop severe chronic obstructive pulmonary disease at younger ages. ${ }^{41}$

Similarly, asthma is impacted by smoking through many mechanisms. Chronic airway inflammation, impaired mucociliary clearance, impaired growth of the lungs during childhood, and increased bronchial hyperresponsiveness are all enhanced by smoking. ${ }^{82,83,55}$ Immunologic mechanisms include effects on $\mathrm{T}$ cell function and a higher ratio of $\mathrm{Th} 2 / \mathrm{Th} 1$, increased production of IgE, and greater allergic sensitization. Cigarette smoke may increase neurogenic inflammation in the bronchial airway ${ }^{84,85}$ resulting in further inflammation of the airway. In summary, the evidence is suggestive of a causal relationship between active smoking and the incidence of asthma in adults as well as exacerbation of asthma among children and adolescents, and adults. ${ }^{41}$ Serious lung infections can also be promoted by smoking. For example, risk of Mycobacterium tuberculosis disease, mortality from the disease and disease recurrence are all higher in smokers. ${ }^{86}$ Lastly, some evidence suggests a possible relationship between cigarette smoking and idiopathic pulmonary fibrosis. ${ }^{87}$

Cigarette smoking causes many other diseases such as diabetes mellitus. The risk of developing diabetes is $30-40 \%$ higher for active smokers than nonsmokers. ${ }^{41}$

There is a positive dose-response relationship between the number of cigarettes smoked and the risk of developing diabetes. Furthermore, smoking aggravates insulin resistance in persons 
with diabetes resulting in suboptimal control of blood sugars. ${ }^{41}$

Recently, smoking was implicated in the pathogenesis of rheumatoid arthritis. The mechanism appears to involve both the effects of oxidizing chemicals in the smoke and the sympathomimetic effects of nicotine. ${ }^{41}$

Neovascular and atrophic forms of age-related macular degeneration are also caused by smoking. Multiple pathways are likely responsible for the degenerative changes in the macula. In genetically susceptible persons, smoking causes changes in retinal pigment epithelium, Bruch's membrane, and choroidal endothelium and generate a local inflammatory response. ${ }^{88}$ Oxidative stress and vascular insufficiency are proposed mechanisms for smoking-related damage to retinal structures. ${ }^{89}$ ,90

Additional evidence is sufficiently conclusive that smoking is associated with many other conditions such as erectile dysfunction, ectopic pregnancy and contributes significantly to infertility in both males and females. Maternal active smoking might be also linked to spontaneous abortion in the mother and orofascila clefts, clubfoot, gastroschisis, and atrial septal heart defects in the fetus. ${ }^{41}$

\section{Tobacco control strategies:}

The WHO through its international treaty the Frame Work Convention on Tobacco control lists six evidence-based strategies that aim to address the various articles in this treaty including policy, regulatory and economic interventions..$^{91}$ Summarized in the word MPOWER, the components stand for the following: Monitor tobacco use and prevention policies. National data are collected periodically to track tobacco use and consumption. The global Adult Tobacco and the Global Youth Tobacco surveys are examples. Unfortunately, many countries in the world are not capable of conducting these surveys due to their high cost.

Protect people from tobacco smoke: Implementing bans on smoking in public places is the corner stone of this strategy. While this has been a very successful strategy in high-income countries to reduce the spread and harms of tobacco, it has been very challenging to implement in low income countries due to the significant lack of governmental commitment and a strong tobacco lobby that has been transferring its markets to those vulnerable regions.

Offer help to quit tobacco use: this strategy will be discussed in details in the following section. Warn about the dangers of tobacco: mass media campaigns as well as the use of pictorial warning are known successful methods to attract public attention, deliver necessary health messages and drive up the intention to quit among smokers. Pictorial warnings on cigarette packs are usually graphic and occupy at least $50 \%$ of the surface area of the cigarette pack. In the Eastern Mediterranean Region, Jordan, Egypt and Iran introduced those warnings and in the process of upgrading them.

Raise taxes on tobacco: this strategy is considered by far the most effective strategy for tobacco control. Typically, national governments would impose high taxes on tobacco products in order to increase the price and making cigarettes less accessible to the public especially children. Revenues from these taxes are then invested in strengthening tobacco control measures, improving customs and border controls, and curbing tobacco illicit trade. Furthermore, such revenues can be invested in building health care systems and train health care providers. Currently, worldwide variation in successful implementation of this strategy exists. High income countries took steady steps in implementing this strategy while low income countries continue to fall for the tobacco industry promises of guaranteed short term profits and discouraged from taking aggressive moves by the misleading evidence provided by the tobacco industry to governments that such profits might be hindered should higher taxes were implemented due to the increase in smuggled tobacco, an action typically promoted and supported by the tobacco industry.

Tobacco dependence treatment and the gains of quitting:

The benefits of quitting occur simultaneously with the cessation of the act of smoking. For example, normalization of the heart rate, blood pressure and decrease in coughing and production of phlegm occurs within hours to days from quitting. ${ }^{92}$

In the long-term, quitting tobacco reduces premature death by $90 \%$ for those who quit before the age of 30 and by $50 \%$ for those who quit before the age of $50 .{ }^{92}$ In five years, the risk of stroke falls to that of a non-smoker, and the risk of head and neck cancers and bladder cancers is reduced by half. ${ }^{93}$ Better control of respiratory diseases like asthma and COPD including symptoms, exacerbations of the disease, hospital admissions and finally mortality form COPD has been clearly 
demonstrated in the literature. ${ }^{94}$ However, despite these documented short and long-term benefits of quitting smoking, and despite listing $O$ - offer help to quit as one of the recommended WHO strategies for tobacco control, tobacco dependence treatment (TDT) services continue to be scarce and inconsistent across the world. Many factors contribute to this shortage of TDT, including the lack of training opportunities for health care providers in basic skills needed to deliver TDT services. Tobacco dependence treatment is an integral component of any comprehensive tobacco control effort. Comprehensive TDT services include the techniques of brief advice, motivational interviewing and counseling, establishing effective quitlines, and availing low-cost pharmacotherapy. In 1999, the World Bank -building on data published by Peto et al. estimated that if adult consumption of tobacco is halved by 2020 the world can prevent about 200 million deaths by 2050. In comparison, the short-term effect on mortality of halving the number of young people who take up smoking was negligible. Accordingly, the report urged governments seeking health and economic gain to encourage smokers to quit. ${ }^{95}$

Likewise, the World Health Organization (WHO) -through Article 14 of the FCTC- mandates parties to design and implement effective programs to promote cessation of tobacco use and provide adequate treatment for tobacco dependence. ${ }^{96}$ The WHO recommends inclusion of cessation advice in primary healthcare services, establishing accessible and free quitlines, and availing lowcost pharmacotherapy. ${ }^{97}$ Inclusion of cessation advice in primary healthcare settings proves to be a low-cost strategy where the major investment is in training of providers and in providing informational materials to tobacco users. ${ }^{97}$

Pharmacotherapy, while more expensive than offering cessation advice, has been shown to double or triple quit rates. ${ }^{97}$ Overall, TDT interventions are extremely cost effective when compared to treatment of other chronic diseases such as hypertension. While a specialist may average two hours for treatment of one tobacco dependence case, treatment of hypertension over the lifetime of the patient consumes more time.$^{98} \mathrm{In}$ general the cost-effectiveness of TDT exceeds that of other commonly provided clinical preventive services, including Pap tests, mammography, colon cancer screening, treatment of mild to moderate hypertension, and treatment of high levels of serum cholesterol. ${ }^{99}$
The American College of Chest Physicians recommends dealing with tobacco dependence as a chronic relapsing condition similar to asthma. Various forms of treatments are used in a controller and reliever fashion. ${ }^{100}$

In most subjects combination pharmacotherapy is used for better outcome. A long acting nicotine replacement therapy (NRT) such as the nicotine patch is usually combined with as needed doses of a short acting NRT such as nicotine gum, lozenges, inhaler or nasal spray. All NRT doses are titrated to control subjects' withdrawal and craving symptoms. Bupropion, an antidepressant and/or varenicline $\left(\alpha_{4} \beta_{2}\right.$ nicotinic acetylcholine receptor partial agonist) are combined with NRT for better control of symptoms and enhanced cessation rates. ${ }^{101}$ In both choices, doses are titrated up over few days to avoid side effects. Treatment is usually continued for at least three months or as long as it is needed. Safety data are now available for the chronic use of all these medication. Relapse is very common in subjects trying to quit smoking and must be addressed early on in the course of treatment. Behavioral and cognitive key techniques in TDT and preventing relapse.

Many challenges face establishing effective tobacco dependence treatment programs. Tobacco education and training in healthcare disciplines continues to be lacking. A 2009 survey of 171 countries indicated that only $27 \%$ of medical schools taught a specific module on tobacco. ${ }^{102}$

However, progress is being made via international collaborations through training HCPs on delivering effective TDT, the EMR continues to face other challenges that hinder service expansion. King Hussein Cancer Center (KHCC), a comprehensive cancer care facility in Jordan that has been offering TDT services to cancer patients and the general public since 2008, recognized early on that such gaps in capacity and competence limit the reach of services and patients' access to help. Realizing the importance of training HCPs in evidence-based treatment, KHCC started in 2011 to offer TDT training to countries of the EMR through collaboration with Global Bridges; an international healthcare alliance for tobacco dependence treatment that was founded by Mayo Clinic, the American Cancer Society, and the University of Arizona. Global Bridges seeks to create opportunities to share treatment and advocacy expertise and to provide state-of-the-art training to help countries fulfill FCTC's Article 14. While other organizations represent Global 
Bridges throughout Latin America, Africa, and Europe, $\mathrm{KHCC}$ is the regional host and partner for Global Bridges in the EMR. To date, KHCC has trained over 1500 HCPs and advocates from EMR on tobacco control and TDT through more than 20 workshops and conferences spanning the region from Morocco to UAE. Political commitment to tobacco control is not uniform across the region, and the tobacco industry (TI) has been gaining traction in some countries. As developed nations tighten their regulations on the tobacco industry, the developing nations of the EMR -with their relaxed tobacco control regulations- present themselves as a safe haven to the TI. While tobacco companies are state-owned in eight EMR countries, ${ }^{1}$ multi-nationals are establishing their operations in other countries such as the situation is in Jordan. ${ }^{103}$

Another challenge that may hinder expansion of TDT services in the region is tobacco use among physicians and other healthcare workers. The prevalence of ever smoking cigarettes among medical students in 2010 in the region ranged between $24 \%$ and $42 \% .{ }^{104}$ This undermines the role that healthcare providers should play in reducing the social acceptability of tobacco use and their credibility in promoting TDT services. ${ }^{105}$ It is thus imperative that teaching and training programs for HCPs address tobacco control and TDT early on, and that special attention is given to helping these professionals quit tobacco use as an initial step. Furthermore, the lack of health coverage by national or private health care plans as well as the inconsistency in the availability of necessary pharmacological drugs use in TDT and the prices of these drugs are all considered real obstacles facing smokers who are trying to quit. In conclusion, tobacco is highly addictive and poses great danger to those who consume it. Dependence and harms of tobacco as well as the benefits of quitting are clearly documented in the literature. International strategies for tobacco control must be implemented globally in effort to lower the prevalence by the year 2040 to less than $5 \%$ worldwide. 
International Journal of Human and Health Sciences Vol. 02 No. 03 July’18

\section{References:}

1. Eriksen M, Mackay J, Ross H. The Tobacco Atlas. Fourth Ed. Atlanta, GA: American Cancer Society; New York, NY: World Lung Foundation; 2012

2. History of Tobacco: http://academic.udayton.edu/ health/syllabi/tobacco/history.htm

3. Eriksen M, Mackay J, Ross H. The Tobacco Atlas. Fourth Ed. Atlanta, GA: American Cancer Society; New York, NY: World Lung Foundation; 2012

4. Mackay J, Eriksen M, Shafey O. The tobacco atlas, 2nd ed. Atlanta, GA,American Cancer Society, 2006.

5. Malson JLet al. Clove cigarette smoking: biochemical, physiological, and subjective effects. Pharmacology, Biochemistry, and Behaviour, 2003,74:739-745.

6. Brody AL, Mandelkern MA, London ED, Khan A, Kozman D, Costello MR, Vellios EE,Archie MM, Bascom R, Mukhin AG. Effect of secondhand smoke on occupancy of nicotinic acetylcholine receptors in brain. Arch Gen Psychiatry. 2011 Sep;68(9):953-60. doi: 10.1001/archgenpsychiatry.2011.51. Epub 2011 May 2.

7. U.S. Department of Health and Human Services. The Health Consequences of Involuntary Exposure to Tobacco Smoke: A Report of the Surgeon General- Executive Summary. Rockville, MD: U.S. Department of Health and Human Services, Centers for Disease Control and Prevention, Coordinating Center for Health Promotion, National Center for Chronic Disease Prevention and Health Promotion, Office on Smoking and Health, 2006

8. Hurt RD, Weston SA, Ebbert JO, McNallan SM, Croghan IT, Schroeder DR, Roger VL. Myocardial infarction and sudden cardiac death in Olmsted County, Minnesota,before and after smoke-free workplace laws. Arch Intern Med. 2012 Nov 26;172(21):1635-41.

9. Comstock GW, Lundin FE Jr. Parental smoking and perinatal mortality. Am J Obstet Gynecol. 1967 Jul 1;98(5):708-18.

10. Colley JR, Holland WW, Corkhill RT. Influence of passive smoking and parental phlegm on pneumonia and bronchitis in early childhood. Lancet. 1974 Nov 2;2(7888):1031-4.

11. White, J. R. and Froeb, H. F.:Small airways dysfunction in nonsmokers chronically exposed to tobacco smoke. N. Eng. J. Med. 302:720-23,1980.

12. U.S. Department of Health and Human Services. The Health Consequences of Involuntary Smoking. A Report of the Surgeon General. Rockville (MD): U.S. Department of Health and Human Services, Public Health Service, Centers for Disease Control, Center for Health Promotion and Education, Office on Smoking and Health, 1986. DHHS Publication No. (CDC) 87-8398.
13. Ballantyne $\mathrm{C}$, What is third-hand smoke? Is it hazardous? Scientific American. January 6, 2009. $<$ http://www.scientificamerican.com/article. cfm?id=what-is-third-hand-smoke $>$

14. Sleiman M, Gundel LA, Pankow JF, Jacob P 3rd, Singer BC, Destaillats H. Formation of carcinogens indoors by surface-mediated reactions of nicotine with nitrous acid, leading to potential thirdhand smoke hazards. Proc Natl Acad Sci U S A. 2010 Apr 13;107(15):6576-81. doi: 10.1073/pnas.0912820107. Epub 2010 Feb 8. )

15. Caryn Rabin, R. , A New Cigarette Hazard - 'ThirdHand Smoke. The New York Times. January 2, 2009. <http://www.nytimes.com/2009/01/03/health/ research/03smoke.html?_r=0 >

16. Matt GE, Quintana PJ, Destaillats H, Gundel LA, Sleiman M, Singer BC, Jacob P,Benowitz N, Winickoff JP, Rehan V, Talbot P, Schick S, Samet J, Wang Y, Hang B,Martins-Green M, Pankow JF, Hovell MF. Thirdhand tobacco smoke: emerging evidence and arguments for a multidisciplinary research agenda. Environ Health Perspect. 2011 Sep;119(9):1218-26. doi: 10.1289/ehp.1103500. Epub 2011 May 31. Review.

17. Sargent, J. D. and DiFranza, J. R. (2003), Tobacco Control for Clinicians Who Treat Adolescents. CA: A Cancer Journal for Clinicians, 53: 102-123. doi: 10.3322/canjclin.53.2.102

18. McNeill AD, West RJ, Jarvis M, et al. Cigarette withdrawal symptoms in adolescent smokers. Psychopharmacology 1986; 90:533-536.

19. World Health Organization. The ICD-10 Classification of Mental and Behavioral Disorders. Clinical Descriptions and Diagnostic Guidelines. Geneva, Switzerland: World Health Organization; 1992

20. Robinson TE, Berridge KC. The neural basis of drug craving: an incentive-sensitization theory of addiction. Brain Res Brain Res Rev. 1993 SepDec;18(3):247-91.)

21. Nutt D, King LA, Saulsbury W, Blakemore C. Development of a rational scale to assess the harm of drugs of potential misuse. Lancet. 2007 Mar 24;369(9566):1047-53.24;369(9566):1047-53.

22. Jordan: http://www.aliftaa.jo/Decision. aspx?DecisionId $=111$

23. KSA http://www.sha.org.sa/arabic/patients info_a/ islam/fatwa_smoking_inhibition.htm

24. Egypt http://www.dar-alifta.org/ViewFatwa. aspx?ID=3699

25. Indonesia http://www.jakartaupdates.com/37smoking-is-haram-muhammadiyah

26. Spanagel R, Weiss F (1999). "The dopamine hypothesis of reward: past and current status". Trends 
Neurosci. 22 (11): 521-7. ㅇi: $10.1016 / \mathrm{S} 0166-$ 2236(99)01447-2.

27. Grenhoff J, Aston-Jones G, Svensson TH. Nicotinic effects on the firing pattern of midbrain dopamine neurons. Acta Physiologica Scandinavica 1986;128(3):351-8.

28. Nisell M, Nomikos GG, Svensson TH. Infusion of nicotine in the ventral tegmental area or the nucleus accumbens of the rat differentially affects accumbal dopamine release. Pharmacology and Toxicology 1994a; 75(6):348-52.

29. Nisell M, Nomikos GG, Svensson TH. Systemic nicotine-induced dopamine release in the rat nucleus accumbens is regulated by nicotinic receptors in the ventral tegmental area. Synapse 1994b;16(1):36-44.

30. Pidoplichko VI, DeBiasi M, Williams JT, Dani JA. Nicotine activates and desensitizes midbrain dopamine neurons. Nature 1997;390(6658):401-4.

31. Pidoplichko VI, DeBiasi M, Williams JT, Dani JA. Nicotine activates and desensitizes midbrain dopamine neurons. Nature 1997;390(6658):401-4.

32. Watkins SS, Stinus L, Koob GF, Markou A. Reward and somatic changes during precipitated nicotine withdrawal in rats: centrally and peripherally mediated effects. Journal of Pharmacology and Experimental Therapeutics 2000;292(3):1053-64.

33. Picciotto MR, Corrigall WA. Neuronal systems underlying behaviors related to nicotine addiction: neural circuits and molecular genetics. Journal of Neuroscience 2002;22(9):3338-41.

34. Balfour DJ. The neurobiology of tobacco dependence: a preclinical perspective on the role of the dopamine projections to the nucleus accumbens [corrected]. Nicotine \& Tobacco Research 2004;6(6):899-912.

35. Gray R, Rajan AS, Radcliffe KA, Yakehiro M, Dani JA. Hippocampal synaptic transmission enhanced by low concentrations of nicotine. Nature 1996;383(6602):713-6.

36. Gioanni Y, Rougeot C, Clarke PB, Lepouse C, Thierry AM, Vidal C. Nicotinic receptors in the rat prefrontal cortex: increase in glutamate release and facilitation of mediodorsal thalamo-cortical transmission. European Journal of Neuroscience 1999;11(1):18-30.

37. Fu Y, Matta SG, Gao W, Brower VG, Sharp BM. Systemic nicotine stimulates dopamine release in nucleus accumbens: re-evaluation of the role of N-methyl-D-aspartate receptors in the ventral tegmental area. Journal of Pharmacology and Experimental Therapeutics 2000;294(2):458-65.

38. Grillner P, Svensson TH. Nicotine-induced excitation of midbrain dopamine neurons in vitro involves ionotropic glutamate receptor activation. Synapse 2000; 38(1):1-9.

39. Mansvelder HD, McGehee DS. Long-term potentiation of excitatory inputs to brain reward areas by nicotine. Neuron 2000;27(2):349-57.

40. Reid MS, Fox L, Ho LB, Berger SP. Nicotine stimulation of extracellular glutamate levels in the nucleus accumbens: neuropharmacological characterization. Synapse 2000;35(2):129-36.

41. Schilström B, Svensson HM, Svensson TH, Nomikos GG. Nicotine and food induced dopamine release in the nucleus accumbens of the rat: putative role of alpha7 nicotinic receptors in the ventral tegmental area. Neuroscience 1998;85(4):1005-9.

42. U.S. Department of Health and Human Services. The Health Consequences of Smoking: 50 Years of Progress. A Report of the Surgeon General. Atlanta, GA: U.S. Department of Health and Human Services, Centers for Disease Control and Prevention, National Center for Chronic Disease Prevention and Health Promotion, Office on Smoking and Health, 2014.

43. Henningfield JE, Keenan RM. Nicotine delivery kinetics and abuse liability. Journal of Consulting and Clinical Psychology 1993;61(5):743-50

44. National Center for Health Statistics. Health, United States, 2012: With Special Feature on Emergency Care. Hyattsville, MD. 2013.

45. Benowitz NL, Hukkanen J, Jacob P 3rd. Nicotine chemistry, metabolism, kinetics and biomarkers. Handbook of Experimental Pharmacology 2009;(192):29-60.

46. Brody AL, Mandelkern MA, London ED, Khan A, Kozman D, Costello MR, Vellios EE,Archie MM, Bascom R, Mukhin AG. Effect of secondhand smoke on occupancy of nicotinic acetylcholine receptors in brain. Arch Gen Psychiatry. 2011 Sep;68(9):953-60. doi: 10.1001/archgenpsychiatry.2011.51. Epub 2011 May 2.

47. Jarvis MJ, Russell MA, Feyerabend C. Absorption of nicotine and carbon monoxide from passive smoking under natural conditions of exposure. Thorax. 1983;38(11):829-833.

48. Martin RJ, Okken A, Katona PG, Klaus MH. Effect of lung volume on expiratory

49. time in the newborn infant. J Appl Physiol Respir Environ Exerc Physiol. 1978

50. Jul;45(1):18-23.

51. Tobin MJ, Chadha TS, Jenouri G, Birch SJ, Gazeroglu HB, Sackner MA. Breathing patterns. 1. Normal subjects. Chest. 1983 Aug;84(2):202-5.

52. Bennett WD, Zeman KL. Effect of body size on breathing pattern and fine-particle deposition in children. J Appl Physiol (1985). 2004 Sep;97(3):8216. Epub 2004 Apr 23.

53. World Health Organization, Global Report, 2012: mortality attributable to tobacco. Geneva, WHO. http://www.who.int/tobacco/publications/ 
surveillance/rep_mortality_attributable/en/

54. Bloom, D.E., Cafiero, E.T., Jané-Llopis, E., Abrahams-Gessel, S., Bloom, L.R., Fathima, S., Feigl,A.B., Gaziano, T., Mowafi, M., Pandya, A., Prettner, K., Rosenberg, L., Seligman, B., Stein, A.Z., \& Weinstein, C. (2011).The Global Economic Burden of Noncommunicable Diseases. Geneva: World Economic Forum

55. World Health Organization, Preventing chronic diseases report , 2005 http://www.who.int/chp/ chronic_disease_report/en/

56. U.S. Public Health Service. Smoking and Health: Report of the Advisory Committee to the Surgeon General of the Public Health Service. Washing-ton, DC: U.S. Government Printing Office, 1964. 33.

57. Goncalves RB, Coletta RD, Silverio KG, Benevides L, Casati MZ, da Silva JS, Nociti FH, Jr. Impact of smoking on inflammation: overview of molecular mechanisms. Inflammation Research 2011;60(5):409-24.

58. U.S. Department of Health and Human Services. How Tobacco Smoke Causes Disease: The Biology and Behavioral Basis for Smoking-Attributable Disease: A Report of the Surgeon General. Atlanta, GA: U.S. Department of Health and Human Services, Centers for Disease Control and Prevention, National Center for Chronic Disease Prevention and Health Promotion, Office on Smoking and Health, 2010.

59. Thun MJ, Carter BD, Feskanich D, Freedman ND, Prentice R, Lopez AD, Hartge P, Gapstur SM. 50year trends in smoking-related mortality in the United States. New England Journal of Medicine 2013;368(4):351-64.

60. National Center for Health Statistics. Health, United States, 2010: With Special Feature on Death and Dying. Hyattsville, MD. 2011..

61. Jefferis BJ, Lowe GD, Welsh P, Rumley A, Lawlor DA, Ebrahim S, Carson C, Doig M, Feyerabend C, McMeekin L, Wannamethee SG, Cook DG, Whincup PH. Secondhand smoke (SHS) exposure is associated with circulating markers of inflammation and endothelial function in adult men and women. Atherosclerosis. 2010 Feb;208(2):550-6. doi: 10.1016/j.atherosclerosis.2009.07.044. Epub 2009 Jul 30.

62. Burns DM. Epidemiology of smoking-induced cardiovascular disease. Prog Cardiovasc Dis. 2003 Jul-Aug;46(1):11-29.

63. McGill HC Jr, McMahan CA, Gidding SS. Preventing heart disease in the 21st century: implications of the Pathobiological Determinants of Atherosclerosis in Youth (PDAY) Study. Circulation 2008;117(9):1216-27.

64. Meijer WT, Grobbee DE, Hunink MG, Hofman A, Hoes AW. Determinants of peripheral arterial disease in the elderly: the Rotterdam Study. Archives of Internal Medicine 2000;160(19):2934-8.

65. Ness J, Aronow WS, Ahn C. Risk factors for symptomatic peripheral arterial

66. disease in older persons in an academic hospitalbased geriatrics practice. J Am Geriatr Soc. 2000 Mar;48(3):312-4.

67. U.S. Department of Health and Human Services. The Health Consequences of Smoking: Cardiovascular Disease. A Report of the Surgeon General. Rockville (MD): U.S. Department of Health and Human Services, Public Health Service, Office on Smoking and Health, 1983. DHHS Publication No. (PHS) 8450204.

68. U.S. Department of Health and Human Services. Women and Smoking. A Report of the Surgeon General. Rockville (MD): U.S. Department of Health and Human Services, Public Health Service, Office of the Surgeon General, 2001.

69. U.S. Department of Health and Human Services. The Health Consequences of Smoking: A Report of the Surgeon General. Atlanta (GA): U.S. Department of Health and Human Services, Centers for Disease Control and Prevention, National Center for Chronic Disease Prevention and Health Promotion, Office on Smoking and Health, 2004.

70. Stallings-Smith S, Zeka A, Goodman P, Kabir Z, Clancy L. Reductions in cardiovascular, cerebrovascular, and respiratory mortality following the national Irish smoking ban: interrupted timeseries analysis. PloS One 2013;8(4):e62063.

71. Mackay DF, Haw S, Newby DE, Langhorne P, Lloyd SM, McConnachie A, Pell JP. Impact of Scotland's comprehensive, smoke-free legislation on stroke. PloS One 2013;8(5):e62597.

72. U.S. Department of Health and Human Services. How Tobacco Smoke Causes Disease-The Biology and Behavioral Basis for Smoking-Attributable Disease: A Report of the Surgeon General. Atlanta (GA): U.S. Department of Health and Human Services, Centers for Disease Control and Prevention, National Center for Chronic Disease Prevention and Health Promotion, Office on Smoking and Health, 2010

73. Ogle KS, Swanson GM, Woods N, Azzouz F: Cancer and comorbidity: redefining chronic diseases. Cancer 2000; 88: 653-663.

74. Thomas W, Holt PG, Keast D: Effect of cigarette smoking on primary and secondary humoral responses of mice. Nature 1973; 243:240-241.

75. Thomas WR, Holt PG, Keast D: Recovery of immune system after cigarette smoking. Nature 1974; 248 : 358-359.

76. Feder M, Siegfried JM, Balshem A, Litwin S, Keller SM, Liu Z, Testa JR: Clinical relevance of 
chromosome abnormalities in non-small cell lung cancer. Cancer Genet Cytogenet 1998; 102: 25-31.

77. Sanchez-Cespedes M, Ahrendt SA, Piantadosi S, Rosell R, Monzo M, Wu L, Westra WH, Yang SC, Jen J, Sidransky D: Chromosomal alterations in lung adenocarcinoma from smokers and nonsmokers. Cancer Res 2001; 61: 1309-1313.

78. Gan X, Zhou Y, Cai L: Prognosis of laryngeal carcinoma in youth (in Chinese). Zhonghua Er Bi Yan Hou Ke Za Zhi 1996; 31: 201-202.

79. Tammemagi CM, Neslund-Dudas C, Simoff M, Kvale P: Smoking and lung cancer survival:the role of comorbidity and treatment. Chest 2004; 125: 2737.

80. Garipidou V, Vakalopoulou S, Zafiriadou E, Kaloutsi V, Tziomalos K, Perifanis V: Uncommon manifestation of bleomycin-induced pulmonary toxicity in a patient with Hodgkin's disease. Ann Oncol 2005; 16: 514-515.

81. O'Sullivan JM, Huddart RA, Norman AR, Nicholls J, Dearnaley DP, Horwich A: Predicting the risk of bleomycin lung toxicity in patients with germ-cell tumours. Ann Oncol 2003; 14: 91-96.

82. Monson JM, Stark P, Reilly JJ, Sugarbaker DJ, Strauss GM, Swanson SJ, Decamp MM, Mentzer SJ, Baldini EH: Clinical radiation pneumonitis and radiographic changes after thoracic radiation therapy for lung carcinoma. Cancer 1998; 82: 842-850.

83. Garces YI, Schroeder DR, Nirelli LM, Croghan GA, Croghan IT, Foote RL, Hurt RD: Second primary tumors following tobacco dependence treatments among head and neck cancer patients. Am J Clin Oncol 2007; 30: 531-539.

84. Do KA, Johnson MM, Lee JJ, Wu XF, Dong Q, Hong WK, Khuri FR, Spitz MR: Longitudinal study of smoking patterns in relation to the development of smoking-related secondary primary tumors in patients with upper aerodigestive tract malignancies. Cancer 2004; 101: 2837-2842.

85. Zhou W, Heist RS, Liu G, Park S, Neuberg DS, Asomaning K, Wain JC, Lynch TJ, Christiani DC: Smoking cessation before diagnosis and survival in early stage non-small cell lung cancer patients. Lung Cancer 2006; 53: 375-380.

86. U.S. Department of Health and Human Services. The Health Consequences of Smoking: A Report of the Surgeon General. Atlanta, GA: U.S. Department of Health and Human Services, Centers for Disease Control and Prevention, National Center for Chronic Disease Prevention and Health Promotion, Office on Smoking and Health, 2004.

87. U.S. Department of Health and Human Services. The Health Consequences of Involuntary

88. Exposure to Tobacco Smoke: A Report of the Surgeon
General. Atlanta, GA: U.S. Department of Health and Human Services, Centers for Disease Control and Prevention, Coordinating Center for Health Promotion, National Center for Chronic Disease Prevention and Health Promotion, Office on Smoking and Health, 2006.

89. Bessac BF, Sivula M, von Hehn CA, Escalera J, Cohn L, Jordt SE. TRPA1 is a major oxidant sensor in murine airway sensory neurons. Journal of Clinical Investigation 2008;118(5):1899-910.

90. Simon SA, Liedtke W. How irritating: the role of TRPA1 in sensing cigarette smoke and aerogenic oxidants in the airways. Journal of Clinical Investigation 2008; 118(7):2383-6.

91. Ariyothai N, Podhipak A, Akarasewi P, Tornee S, Smithti- karn S, Thongprathum P. Cigarette smoking and its relation to pulmonary tuberculosis in adults. South- east Asian Journal of Tropical Medicine and Public Health 2004;35(1):219-27

92. Baumgartner KB, Samet JM, Stidley CA, Colby TV, Wal- dron JA. Cigarette smoking: a risk factor for idiopathic pulmonary fibrosis. American Journal of Respiratory and Critical Care Medicine 1997;155(1):242-8

93. Wang AL, Lukas TJ, Yuan M, Du N, Handa JT, Neufeld AH. Changes in retinal pigment epithelium related to cigarette smoke: possible relevance to smoking as a risk factor for age-related macular degeneration. PloS One 2009a;4(4):e5304.

94. Rahman I, MacNee W. Role of oxidants/antioxidants in smoking-induced lung diseases. Free Radical Biology and Medicine 1996;21(5):669-81.

95. Bettman JW, Fellows V, Chao P. The effect of cigarette smoking on the intraocular circulation. A.M.A. Archives of Ophthalmology 1958;59(4):481-8.

96. World Health Organization. Controlling the Smoking Epidemic. Report of the WHO Expert Committee on Smoking Control. World Health Organization Technical Report Series No. 636. Geneva (Switzerland): World Health Organization, 1979. Available: http:// whqlibdoc.who.int/trs/WHO TRS 636.pdf

97. National Cancer Institute. Factsheet on harms of smoking and health benefits of quitting. http:// www.cancer.gov/cancertopics/factsheet/Tobacco/ cessation) Accessed: Feb 2014

98. American Cancer Society. Guide to quitting smoking. $\quad$ http://www.cancer.org/healthy/ stayawayfromtobacco/guidetoquittingsmoking/ guide-to-quitting-smoking-benefits Accessed: Feb 2014.

99. Godtfredsen NS, Vestbo J, Osler M, Prescott E. Thorax. 2002 Nov;57(11):967-72. Anthonisen NR, Skeans MA, Wise RA, Manfreda J, Kanner RE, Connett JE; Lung Health Study Research Group. Ann 
International Journal of Human and Health Sciences Vol. 02 No. 03 July'18

Intern Med. 2005 Feb 15;142(4):233-9.

100. Jha P, Chaloupka FJ. Curbing the epidemic: governments and the economics of tobacco control. Washington DC: World Bank.

101. World Health Organization. Protocol to eliminate illicit trade in tobacco products. Geneva: World Health Organization. http://apps.who.int/iris/ bitstream/10665/80873/1/9789241505246 eng. pdf?ua=1)

102. WHO Report on the Global Tobacco Epidemic, 2008: The MPOWER package. Geneva, World Health Organization, 2008

103. Hughes JR. Tobacco Treatment Specialists: A New Profession. Journal of Smoking Cessation 2007; 2:2-7.

104. U.S. Department of Health and Human Services. Reducing Tobacco Use: A Report of the Surgeon General-Executive Summary. Atlanta, Georgia: U.S. Department of Health and Human Services, Centers for Disease Control and Prevention, National Center for Chronic Disease Prevention and Health Promotion, Office on Smoking and Health, 2000.

105. McLellan AT, Lewis DC, O'Brien CP, et al. Drug dependence, a chronic medical illness: implications for treatment, insurance, and outcomes evaluation. JAMA. 2000 Oct 4;284(13):1689-95.

106. Cahill K, Stead LF, Lancaster T. Nicotine receptor partial agonists for smoking cessation. Cochrane Database Syst Rev. 2012 Apr 18;4:CD006103.

107. Richmond R, Zwar N, Taylor R, Hunnisett J, Hyslop F. Teaching about tobacco in medical schools: a worldwide study. Drug Alcohol Rev. 2009 Sep;28(5):484-97.

108. Awraq Investments. Al-Eqbal Investment Company Equity Report. 2011. http://www.awraq.com/uploads/ ch/033a1e112edd533f5ef22504ed856594740a1c88. pdf Accessed: Feb 2014

109. World Health Organization. Global Health Professions Student Survey fact sheets and country reports. http://www.emro.who.int/images/stories/tfi/ documents/GYTS_FS JOR_2009.pdf Accessed: Feb 2014

110. Guidelines for implementation of Article 14 of the WHO Framework Convention on Tobacco Control. http://www.who.int/fctc/guidelines/adopted/ article 14/en/ Accessed: Feb 2014 